\title{
On Philosophy and the Sciences in Antiquity
}

Andrew Barker

andrewqbarker@hotmail.com

Robert Sharples' Philosophy and the Sciences in Antiquity ${ }^{1}$ collects the papers delivered at a colloquium at University College London in 2003. No matter how precisely the organizer defines the subject to which such a colloquium is dedicated, the collected papers that emerge from it rarely add up to a unified whole; contributors go their own ways, sometimes with scarcely a nod to the theme that was intended to unify their efforts. The title 'Philosophy and the Sciences in Antiquity' is enormously capacious, and in itself points to no integrated set of questions and no one line of enquiry, so that readers looking for a cohesive treatment of a single theme may well come to it - in the words of Sydney Smith - 'with no very lively hope of success'.

In fact, however, the agenda set for the authors of these papers was more precisely outlined than the book's title suggests. The editor, Robert Sharples, explains it as follows:

The aim of the present volume, and of the colloquium from which it took its origin, is to examine the relation between philosophy and the individual sciences from the perspective of the ancients themselves, in so far as this is possible. How did they understand this relation, and how did they make use of it in argument and debate? Considering this will also throw light on the process by which, historically, specialist areas of study of the natural world - 'sciences' - became detached from philosophy and obtained an autonomy of their own. It may indeed ... be more accurate to describe the process as one by which philosophy itself came to have a more clearly defined agenda. [3]

1 R.W. Sharples, ed. Philosophy and the Sciences in Antiquity. Keeling Series in Ancient Philosophy. Burlington, VT/Aldershot, UK: Ashgate 2005. Pp. vii + 168. ISBN 0-7546-5171-1. Cloth $\$ 89.85$.

(C) 2009 Institute for Research in Classical Philosophy and Science All rights reserved 
A quibbler might object that several contributors to the volume have allowed themselves some latitude in interpreting this specification of the project, by focusing on relations between particular sciences rather than on those between the sciences and philosophy. But the objection can be dismissed. Negotiations between one scientific discipline and another are part of the process by which they 'obtained an autonomy of their own'; and in any case, the collection attains a surprising level of thematic coherence. Each writer pursues a different set of issues; and the essays address a very diverse selection of sciences, differently conceived varieties of philosophy, and chronologically widespread phases of the disciplines' development. No clear and coherent set of conclusions emerges from their reflections, unless, perhaps, it is to do with the powerful and progressively increasing influence of mathematics both on philosophy and on the natural sciences. But on the basis of the work done in these papers, one can build up an enlightening picture of the intricate network of interactions that took place between the various disciplines, the ways in which barriers were erected between them and broken down, the raids made by one specialism on the territory of another, the claims made by some to authority over others, and, over the centuries, the gradual molding and remolding of the profiles of each of them, especially the most elusive and Protean of them all, philosophy.

Of the seven papers included in the volume (together with Sharples' admirable introduction), the most wide-ranging is the first, an essay by André Laks entitled 'Remarks on the Differentiation of Early Greek Philosophy' [8-22]. Laks first draws attention to an ongoing debate about whether, and if so to what extent, 'pure' science and 'pure' philosophy were treated as distinct specialisms in the sixth and fifth centuries BC, and studied only (or mainly, or often) by dedicated 'professional' specialists [8-9]. He cites Zhmud [1994] as a champion of the view that 'the specialization of science and philosophy happens in Greece astonishingly early', and Lloyd [2002] as one of its notable opponents; but he notes, correctly, that the issue between the two sides is complex and slippery, and that they may not in fact be as radically divergent as they appear at first sight. Some of the teasing ambiguities and complexities are well brought out in later parts of the paper. 
Among the difficulties facing anyone looking for a definitive solution to the problem is the fluidity of the boundaries between disciplines. Laks argues[10], if I understand him rightly, that we shall get nowhere if we treat a situation in which these borderlines are indeterminate as flatly incompatible with one in which distinct specialisms are recognized and their autonomy is proclaimed, and if we then try to decide which situation existed in the time of the Presocratics. Worthwhile results are more likely to be achieved if we concentrate instead on the dynamics of the process by which the various disciplines gradually and in different degrees acquired distinct identities, even though the boundaries they assign to themselves may continue to be contested and the territory they claim repeatedly invaded by others. He notes also, in this context, that philosophy is a special case. Though sciences such as medicine and mathematics change dramatically over the course of time, they are still recognizably concerned with the same subject matters. Philosophy, by contrast, had to be invented from the ground up; earlier and later versions of it are not simply different approaches to the same subjects. The question 'What is philosophy and what is it about?' is vigorously alive to this day; and it would be rash to assume that when fifth-century Greeks referred to $\varphi \iota \lambda o \sigma o \varphi i \alpha$ and drew distinctions between it and other intellectual enterprises, they invariably had the same conception of it or its subject matter in mind.

Laks asserts the right "to describe as "philosophical" some brand of intellectual activity that antedates the appearance of the word itself' [11]. But as a way of identifying the kinds of activity that were regarded in this light, he next considers three of the earliest passages

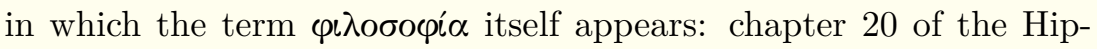
pocratic On Ancient Medicine, Gorgias' Encomium of Helen 13, and Plato's Euthydemus 305c (which is included as a chronologically relevant allusion because its remarks about philosophy are attributed to the sophist Prodicus) [11-15]. In each of these passages, philosophy is pointedly distinguished from some other discipline or disciplines; but on what basis? In the Euthydemus, the answer seems fairly straightforward. The distinction is between the theoretical activities of the philosopher and the practical activities of the politician: the former aims at understanding; the latter, at appropriate action. Gorgias' view is more elusive: he contrasts the $\lambda$ óror of the 'meteorologists' 
(whom Laks plausibly identifies with students of nature) and the contests ( $\not \gamma \tilde{\omega} \nu \varepsilon \varsigma)$ of judicial arguments with the argumentative competitions $(\alpha \mu \iota \lambda \lambda \alpha \iota)$ of philosophers. Competition is evidently involved in both the second and the third, and as Laks says, it is 'certainly not incompatible with meteorology'; and he suggests that philosophy is really being distinguished by the openness of its subject matter, 'any subject which might point to semantic and logical problems' [13].

This conclusion seems at best uncertain, and I am still less convinced by Laks's reading of the passage from On Ancient Medicine. He interprets its contrast between philosophy and medicine as essentially a distinction between the theoretical and the practical; medicine, unlike philosophy, aims at action, 'changing the state of the world' [12]; hence, it corresponds closely to the distinction drawn in the Euthydemus. But that is not what the writer says, or not in this

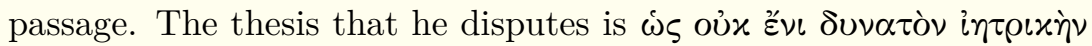

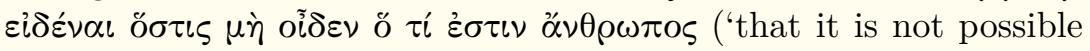
to know medicine if one does not know what man is'). What proponents of this view are talking about, he says, is philosophy, and he

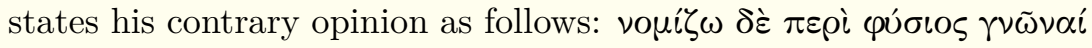

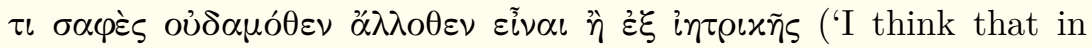
order to have some precise knowledge of nature, there is no other source than medicine'). This opinion, as it seems to me, could only be plausible if the 'nature' to which it refers is, or includes, that of a human being, and in that case the principal goal being attributed to both philosophy and medicine is the same, knowledge of 'what man is'. Whatever one might conclude from other parts of the treatise, the distinction made here between the two disciplines is not between their subject matters or their aims, or between the theoretical and the practical; it is to do with their methods, their approach to the issues that concern them both. According to the philosophers, as I understand them, one must know what man is before one can become expert in medicine; according to the writer, knowledge of the 
nature of man can only emerge from the study of medicine itself. ${ }^{2}$ Laks interprets the writer's comments on Empedocles and the enigmatic allusion to $\gamma \rho \alpha \varphi \iota x$ (painting), which intervene between the two statements, in a way designed to support his claim to detect a contrast between the theoretical and the practical. It would take too long to investigate his interpretations here, and I shall say only that I find them unpersuasive.

I have devoted a disproportionate amount of space to these opening pages of Laks's paper, despite my resistance to some of his views, because they provide a useful introduction to the problems discussed in the remainder of the volume. It is natural to assume that any attempt to examine the relations between the various disciplines must begin by identifying them unambiguously and distinguishing one from another. Whatever else may be said about Laks's remarks, they and the texts he cites bring out very clearly the difficulties into which this assumption will lead us, and why in the case of the early period at least, an approach presupposing that each nameable discipline has, as it were, a definable 'nature' or 'essence' is sure to fail. If our purpose is to reach a view of these intellectual activities 'from the perspective of the ancients themselves', as Sharples puts it, we must focus as steadily as possible on the ways in which the Greek writers actually represent the relevant distinctions, however nebulous or perverse they may seem. It would be a serious error to elide their inconsistencies or apparent eccentricities, to force precision on distinctions that they leave vague or to give sharp outlines to notions which in their hands are malleable and amorphous, or to allow our interpretations to be colored by our own conceptions of the disciplines and their boundaries - or by those of Greek writers working in different periods from the one with which we are currently concerned. It is to the credit of the scholars represented in this collection that they rarely succumb to any of these seductive temptations, or not without explaining what they are doing and why.

2 This is not far from the position which Laks later attributes to Diogenes of Apollonia, though they are arguably not identical:

One could say that in Diogenes' case, doing philosophy implies doing medicine, in the same sense that in Aristotle's case, doing first philosophy implies doing astronomy - up to a certain point, perhaps. [18] 
The distinctions that Laks goes on to draw between 'professionalization', 'specialization' and 'differentiation' [15-18] are ones that anyone working in this area would do well to bear in mind; they will help to keep a number of potential confusions at bay. 'Professionalisation', in his usage, presupposes an institutional framework of some sort, a 'school', and is unlikely to be relevant to the context of the sixth and fifth centuries; it also implies a substantial degree of 'dedication to a single activity'. A 'specialist' is someone who claims a particular field of competence. It need not be his only one (Empedocles and Diogenes, for instance, would probably have claimed several), and it implies no institutional affiliations. Both professionalisation and specialization are categories that apply to persons; 'differentiation', in Laks's sense of the word, is not. It applies to disciplines or fields of competence, and these may be differentiated even when there are no people who are specialists in them. When there are differentiated fields the same person may be a specialist (or we might say, an 'expert') in several, a qualification emphatically claimed for himself by the sophist Hippias, for example.

Laks points out also that fields of competence which are externally differentiated from others may also be internally differentiated into various sub-disciplines (whose status in the field and whose borderlines may themselves be subjects of dispute). The relations between the sub-disciplines and the larger field become especially complex and elusive in the case of philosophy, since some of the disciplines which an exponent asserts or implies that it contains may be ones which other writers, or the same writer elsewhere, represent as distinct from philosophy. Thus, philosophy may at one level be externally differentiated from medicine, and yet it seems that in the view of Diogenes of Apollonia doing medicine is an essential part of a philosopher's business.

Hence, the dichotomy between external and internal differentiation is less straightforward than one might suppose; and it becomes even more complex when we turn to the work of fourth-century philosophers, especially Aristotle. At the end of his paper [18-21], Laks tries to shed some light on the ways in which science and philosophy are differentiated in Aristotle's writings and elsewhere by considering the relation in which the two of them are said to stand to a third category, myth. He finds in a passage of Epicurus the 
implication that 'myth is not a genre, but a function', which he describes as 'extremely appealing'; and he suggests that the same may be true of science and philosophy. He amplifies these rather gnomic remarks by characterizing 'science' and 'philosophy' as 'alternate and legitimate descriptions of the same activity, depending on how you construe science and philosophy' [19]. This seems entirely unobjectionable. But except in so far as it sounds a renewed warning against the allure of fixed and determinate categories into one or another of which each discipline unambiguously falls, I do not see that it greatly advances the discussion of these troublesome issues.

In his opening paragraph, R. J. Hankinson sketches the problem he addresses in his paper, 'Aristotle on Kind-Crossing' [23-54].

In a number of places, Aristotle seems to state unequivocally that no science can make use of the principles of any other science in its demonstrations. Elsewhere, however, he seems not only to countenance such borrowings, but on occasion to make them an essential feature of the construction of scientific explanations. And since science is, for Aristotle, fundamentally an explanatory exercise, this is a particularly uncomfortable position to be in. In this paper I seek to offer an interpretation of Aristotle's views on the issues that tries at least to minimize the tensions involved. [23]

Here, then, we are not concerned with the relations between the sciences and philosophy but with those between the individual sciences, and specifically with the ways - or the senses - in which they can and cannot draw on one another's principles when performing their explanatory tasks. The problem that Hankinson identifies arises mainly from passages in the Posterior Analytics. It is notoriously troublesome and has often been tackled before, ${ }^{3}$ but no consensus about its solution has been reached.

I shall say little about the first two sections of the paper [2343], valuable though they are. They give a very clear account of Aristotle's general theory of scientific demonstration ( $\alpha \pi \delta$ ó $\left.\iota \xi_{\iota \varsigma}\right)$, and a meticulous analysis of the passages from which the difficulties arise.

3 See for instance Lennox 1986, McKirahan 1992, and the commentary in Barnes 1994, all of which are cited, with many others, in Hankinson's bibliography; one might now add Barker 2007, 353-361. 
One important point which Hankinson brings out [esp. 38-40] is that the cases in which a science seems to borrow principles from outside its own domain are of two sorts. In one kind of case, science A is subordinate to science B and draws on some of B's principles in constructing its demonstrations; harmonics, for instance, is subordinate to arithmetic in this way, and optics to geometry [e.g., Post. an. $75 \mathrm{~b} 16,76 \mathrm{a} 10,24,78 \mathrm{~b} 37-8]$. In the other, demonstrations in several sciences which do not fall into such a hierarchy make use of more general principles which are specific to neither of them, as geometry and arithmetic both make use of the axiom of equality (particularly 76a37-b2). In their different ways, both kinds of relation seem to fly in the face of Aristotle's repeated insistence that all the principles used in a scientific $\alpha \pi \delta$ ó $\varepsilon ı \xi_{\iota \varsigma}$ must be proper and peculiar to the domain of the science in question.

At the beginning of the third part of his paper [43-47], Hankinson sums up the situation as he has analyzed it.

The principles of any science will be proper to that science. They will consist in part of $\mathrm{I}_{1}$ predications ${ }^{4}$ which are by definition ... proper to it; and if they also make use of existence assumptions ... those assumptions too will be tied to the domain in question (there is no room in anthropology for propositions like "there are frogs"). Hence, the sciences ought to be (and Aristotle argues that they are) hermetically-sealed; and there will be no kind-crossing.

Yet somehow there can be, at least 'in a way', as is indicated at Post. an. $75 \mathrm{~b} 8-11$ :

The domain must either be the same without qualification, or at least in a way, if the demonstration is going to cross; and it is clear that it is impossible in any other way, since the extreme and the middle terms must be from the same domain.

4 Hankinson [27] adopts the label ' $\mathrm{I}_{1}$ predication' from Barnes [1994, 11214]; 'I' abbreviates 'in itself'. Barnes, following Philoponus, formalizes it as follows: in an $\mathrm{I}_{1}$ predication, 'A holds of $\mathrm{B}$ in itself $=\mathrm{df}$. A holds of $\mathrm{B}$ and $\mathrm{A}$ inheres in the definition of B'. This is distinguished from an $\mathrm{I}_{2}$ predication (in which $\mathrm{A}$ holds of $\mathrm{B}$ and $\mathrm{B}$ inheres in the definition of $\mathrm{A}$ ), but as Hankinson says, 'it is the $\mathrm{I}_{1}$ cases which are the more important'. 
Hankinson points out that the extreme and middle terms include all the terms figuring in the demonstrative syllogisms, and that if they are not all from the same domain there will be no scientific explanation. 'Now', he continues,

if the domain is 'the same without qualification', then there are no kinds to cross; but there may be if it is the same 'in a way'. What might that mean? [43]

This, as it seems to me, is exactly the right question to ask, since it keeps in view a point that might easily be missed. Even when kind-crossing is in play in a legitimate demonstration, all the terms employed will still in some way belong to the same domain, even though in some other way they do not. In no case are we faced with a successful demonstration using terms which belong without qualification to different domains. The challenge is to work out what the relevant qualifications could be.

In moving towards his solution to the problem, Hankinson focuses mainly on one of the two types of case, that in which several sciences which are not subordinate to one another draw on principles which — in one perspective at least — are peculiar and proper to none of them.

Of the things which are used in the demonstrative sciences, some are proper to each science while others are common; but common in virtue of analogy, since they are useful only insofar as they belong to the domain which falls under the science. [Post. an. 76a37-40]

Hankinson explicates this through an example.

In other words, if I make use of the equals axiom in an arithmetic proof, I make use of it in its arithmetic form

(EA) Equal numbers subtracted from equal numbers leave equal numbers,

rather than in that of its Euclidean generalization

(EG) Equals subtracted from equals leave equals. [45]

He next considers and rejects the objection that in such a case EA will lack a feature that is essential to the premises of a demonstration; 'EA is not primitive and immediate, since it can be shown 
to be a consequence of EG'. He argues that even if EA can be derived from EG, this cannot be done within the science of arithmetic itself. Suppose that the first premise of such a derivation runs like this (Hankinson apologizes for the cumbersome formulation):

being such that, when equal and when subtracted from equals, equals remain, belongs to all magnitudes,

and that the second is:

magnitude belongs to all numbers.

From these we can indeed infer something equivalent to EA. But the first premise is clearly not proper and peculiar to arithmetic, and within the restricted domain of that science alone EA cannot be demonstrated, or 'thickened' by the insertion of a middle term. If there is a science to which the first premise belongs it is the more general science of quantity or magnitude, and it will hold per se in that science, not in arithmetic as such. Hence, within arithmetic, EA is underived, primitive, and immediate; and when various different sciences use their own versions of EG, the principles that they use are not identical but are related by way of analogy, as Aristotle says; 'their domains are different, but certain separate facts about the separate domains are structurally isomorphic with one another' $[46] .^{5}$

This leads Hankinson to an important conclusion.

Whenever anyone derives EA as a special case of EG, he does so not as an arithmetician, but as a quantity-theoristand similar strictures hold when one employs geometrical reasoning in optics or mechanics, or arithmetical reasoning in harmonics. Moreover, this analysis has the further advantage of minimizing the distance between the subordinate cases [i.e. ones such as those just mentioned] and those involving coordinate science (such as arithmetic and geometry in the case of proportional alternation): for the latter can now be seen to be a complex type of the former - there is a superordinate

5 Here Hankinson notes the prominent use of 'analogy' in Aristotle's biological works, saying that the sense in which 'analogy' is employed there is the same as the one involved in Post. an.76a. If he is right about that (he does not argue the point), a thorough exploration of the biological analogies might help to clarify further his thesis about the relation between scientific domains and perhaps to give it additional support. 
science, quantity-theory, which provides the explanation as to why the interpreted principles hold in two subordinate sciences. [47]

As he states it, this conclusion seems too weak; so far as I can see it is not just that the distance between the two types has been minimized but that there is now no significant difference between them at all. In every case, a subordinate science makes use of a principle proper to a higher science, but uses it only in a form restricted to the contents of its own domain; and in every case the 'higher' science is also more general, and can be used in parallel ('analogous') ways by several sciences of more restricted scope. ${ }^{6}$

The fourth and final part of Hankinson's paper [47-52] addresses a problem which his interpretation must face, as indeed must any other; it is set in front of us most directly (though not only) by Post. an. 78b35-79a6. Here Aristotle asserts, among other things, that in at least some cases where one science is subordinate to another, it is the task of the lower science to present the facts, and for the higher to provide the explanations. Since the higher science (e.g., geometry) makes no reference to the factual data that are the special province of the lower (e.g., optics), it cannot explain them by itself; and the lower science, it now appears, can provide no explanations at all. But there must be something wrong with this scenario, since Aristotle regularly insists that all the sciences as such are in the business of explaining their data. Hankinson, therefore, follows Ross in his contention that the subordinate discipline, which is merely a collection of empirical data, 'is only by courtesy called a science' [48-49: cf. Ross 1949, 555]; to put it more bluntly, it is not really a science at all.

This seems an unhappy conclusion, not least because in passages where Aristotle mentions such disciplines he seems to have no qualms about representing them as sciences ( $\dot{\pi} \tau \iota \tau \tau \tilde{\eta} \mu \alpha \iota)$ without qualification. In the passage we are discussing, for instance, he tells us that the reason ( $\tau$ ò $\delta \iota o ́ \tau \iota)$ differs from the fact ( $\tau$ o ő $\tau \iota)$ in that-in the cases under consideration - 'each of them is studied by way of a

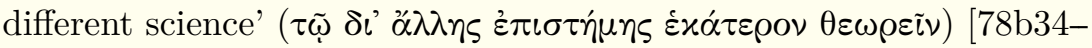

6 This will remain true even if scientists actually recognize only one science subordinate to it; since its domain is wider than that of the lower science, it is logically bound to make room for at least one other subordinate, even if in fact none is practised. 
5]; and it would seem, at least on the face of it, that on Ross's view, every one of the disciplines which Aristotle treats as 'subordinate' in this sense must be expelled from the catalogue of the sciences. We should surely hesitate before consenting on Aristotle's behalf to so draconian a purge. Might it be the case, for instance, that though there are facts falling within the subordinate science's domain which it cannot explain without help from above, there are some such facts which it is capable of explaining unaided, and that its explanatory power in those cases is enough to preserve its scientific credentials?

This suggestion leads to fairly obvious difficulties of its own. I shall not pursue them or argue in favour of the hypothesis here; but perhaps the problems it encounters are no more vexing than those that Ross's involves; and I mention it only by way of an indication that when we are looking for a way of understanding the status of the subordinate disciplines, there might be alternatives to the strategy that he proposes. Now while he accepts Ross's view about this, Hankinson also adds a new twist. He notes that

Aristotle appears to countenance a three-stage hierarchy of at least some of the sciences: just as optics stands to geometry, so "the study of the rainbow" stands to optics in general; and similar hierarchies seem to be constructible for harmonics and possibly also for astronomy. $[48]^{7}$

As an example, he suggests an analysis of an explanation of the phase-structure of the Moon.

7 This contention might be challenged in the case of harmonics. In the relevant passage [Post. an.78b35-79a2], Aristotle says first that harmonics is subordinate to arithmetic, and then that 'harmonics based on hearing' (i.e. empirical harmonics) is subordinate to mathematical harmonics. This may seem to encourage Hankinson's postulation of a three-part hierarchy, and it would perhaps be quibbling to object that Aristotle does not specify that it is mathematical harmonics which is directly subordinate to arithmetic. The real difficulty is that he presents the second statement as specifying one of

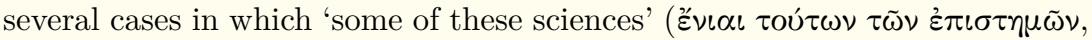
that is, some of the pairs of sciences that have just been mentioned) have 'almost the same names'. This seems to imply that in the present context the references to arithmetic and harmonics on the one hand and to mathematical harmonics and harmonics based on hearing on the other are alternative designations of the same pairs of sciences; and in that case the three-part hierarchy evaporates. 
The first stage is simply to observe and record its regularity (this would belong to observational astronomy). Next comes the hypothesis that the moon is spherical, which, along with other facts ... will account for the appearances. That hypothesis (since it concerns the moon) is proper to astronomy, but to mathematical rather than observational astronomy - and it explains the fact in the familiar manner. But it does so by applying a perfectly general theorem of geometry .... [49]

We are to understand, of course, that it does not apply it in its full generality, but in a way restricted to the astronomical domain; in its restricted form it is related to the general theorem in the same way that the proposition labelled EA above is related to EG.

Thus, mathematical harmonics is 'intermediate between observational astronomy and pure geometry'. That seems a reasonable conclusion and the overall picture seems to capture much of what Aristotle says, though it will still leave observational astronomy, harmonics, and so on in a non-scientific limbo. But there is perhaps a residual problem about the complex 'intermediate' science. Hankinson points out that Aristotle is right in saying that an exponent of the highest of the three disciplines need not be aware of any of the facts stated by its subordinates, since its propositions are set in a generalized form which refers to none of them. But it is not clear that the same can be true of mathematical astronomy in relation to its subordinate, observational astronomy. The mathematical astronomer's demonstrations must refer to the facts to be explained, that is, to the facts collected by his observational counterpart; and if the demonstrations mention and explain these facts, the demonstrator must surely 'know' them, as indeed Hankinson implicitly concedes: 'Unlike the observational astronomer, who ... merely knows the facts, the mathematical astronomer understands them' [49]. If he understands them, I presume, he must know them. Yet just after mentioning the two kinds of astronomy, Aristotle has said that in such cases

it is for the observational sciences to know the facts and for the mathematical ones to know the reason why; for the latter possess the demonstrations of the reasons why, while they are often unaware of the fact. [Post. an. 79a2-4]

I do not know how this difficulty should be resolved. In much of the remainder of Hankinson's paper, he focuses on a rather strange 
example of kind-crossing in which an explanation appeals to propositions of two sciences, medicine and geometry, neither of which, so Aristotle asserts, is subordinate to the other, prefacing his assertion with the remark that there are many cases of this sort [Post.an. 79a13-16]. Hankinson shows, convincingly, I think, that such cases can be acquitted of breaching Aristotle's rules in much the same way as the others.

The argument supplying the reason for the fact will have geometrical content; but in exactly the same way as in the cases of the genuine subordinate sciences such as optics, that content will be formal only; the material will be specified by the domain, and the formal principle ... particularized to medicine. [51]

If the suggestions he makes about the subordinated sciences are acceptable, there seems no good reason why they should not be stretched to accommodate these cases too.

James Lennox begins his paper, 'The Place of Zoology in Aristotle's Natural Philosophy' [55-71], with a barrage of questions. How are Aristotle's books about animals related to one another? How are they situated within his natural philosophy? Does he think of them as a unified investigation, and if so how should we conceive this unity? How are all these studies related to his other investigations of nature? Should various other writings, the De anima and the Parva naturalia, for instance, be included among his works on animals? Here, then, we move from examinations of the relations holding between philosophy and the sciences in general to questions directed to a single, though at this stage uncertainly defined group of writings by a single author; and the spotlight also shifts away from Aristotle's logically motivated rules governing relations between the principles and demonstrations of different sciences (though it will return to them in the paper's closing pages), to the broader conceptual relations and forms of classification which emerge, less directly, from his actual investigations in one scientific domain.

Since Aristotle nowhere addresses these questions head-on, Lennox proceeds on the basis of clues given in passages of certain particular types. Passages of the first type that he discusses [56-59] are those which give cross-references from one work to another within the 
corpus concerned with the study of animals. He dismisses the common notion that these can provide a guide to the works' chronology; what he is looking for is 'a better understanding of the internal conceptual and methodological relationships' that Aristotle envisages between his various zoological enterprises [56]. In practice, he discusses in detail only two passages at this stage, both from the $D e$ partibus animalium [640a10-22,689a4-20]. These passages refer us to studies undertaken in the De generatione animalium; and Lennox' first important point is that all 10 such references in De part.an. look forward from that work to the other, suggesting that De part. an. is in some sense prior to De gen. an., though this entails nothing about the order in which the studies were carried out or the treatises written.

The reason why De part. an. is prior to De gen. an., Lennox argues, is that 'the study of generation must be posterior to the study of that which is to be generated-generation is for the sake of being; being is the cause, coming into being the effect...'; and this 'reflects Aristotle's peculiarly teleological understanding of the methodological/conceptual structure of animal inquiry' [57]. This represents faithfully what Aristotle says in the passage at 640a, which ends with his well-known criticism of Empedocles for reversing the true order of priority. ${ }^{8}$ But the relation seems to become more complex in the passage at $689 \mathrm{a}$. Here Aristotle twice explains features of animal anatomy by reference to facts which, he says, we must assume here and prove later, and which are elaborately established in De gen. an. As Lennox says, these allusions clearly point forward from De part. an. to De gen. an., like the remarks at 640a; but he says nothing here about their implications concerning the conceptual relations between the two enterprises. Readers may be left wondering how explanations in De part.an., which is concerned with the final form, can depend on demonstrations that will be provided in De gen. an., whose business is with the processes whereby that form is reached, if indeed 'being is the cause, coming into being the effect'. At a superficial

8 Empedocles' error is exemplified by his explanation of the segmented character of the backbone: it gets broken by being twisted during the process of generation. Features of the generative process are thus used to account for the animal's final form, whereas in fact, according to Aristotle, it is the final form to be achieved that explains this process' characteristics and the course it takes. 
glance, reliance on facts to do with generation to explain facts about the fully-formed animal's structure might seem to involve the Empedoclean error. Some of Lennox' later remarks, however, may help to clarify the issue (see further below).

He draws an important conclusion from the closing lines of the passage. Aristotle refers there to two other investigations relevant to the subject of generation in addition to those contained in De gen. an.: the 'enquiry about animals' (i.e., the studies recorded in the Historia animalium) and the 'dissections' (the topic of a work that is lost). These two 'will make apparent (i) the arrangement of the internal organs connected with generation and (ii) their differences from one group of organisms to another'. These facts will then be reported (not 'explained') in De gen. an., 'which will then define the male and female contributions to generation and demonstrate their properties'. The task remaining for the investigations recorded in De part.an. is to 'show that the configuration of these parts is determined in relation to their activities' (or as Aristotle puts it, 'the configuration of these parts is necessarily for their activity' [De part. an.689a1920]). Hence, Lennox concludes, 'each of the four works makes a distinct contribution to an understanding of the reproductive organs of blooded organisms' [58].

In elaborating this conclusion, he points out that the 'histories' and 'dissections' are not referred to as sources of explanation, but in effect as databases organized with a view to their purposes within a larger scientific framework. ${ }^{9}$ By contrast, as we have seen, De part. an. is clearly in the business of explanation: it explains teleologically facts recorded in those databases, and also on occasion takes for granted facts to be proved in De gen. an., even though that work 'is to be studied after De part. an.' [58-9]. Perhaps Lennox would say, then, that the status of these facts is closely comparable to that of those taken from the databases, and that the difficulty raised by this passage's earlier cross-references from De part. an. to De gen. an. is only apparent. The former's reliance on facts that 'will be proved' ( $\delta \varepsilon \iota \chi \theta \dot{n} \sigma \varepsilon \tau \alpha \iota)$ in the latter does not undermine De part. an.'s methodological and conceptual priority, since it still has the role of providing the fundamental explanations, even for facts 'proved' in

9 Gotthelf 1988 and Lennox 2001 make important contributions to an understanding of their mode of organization. 
De gen. an. In the relevant passage of De part. an., they are used to account for other anatomical facts and in that sense they are relied on; but they do not account for those facts teleologically and, therefore, do not explain them in the required sense. Similarly, the proofs in De gen. an. do not amount by themselves to adequate explanations, and none of these facts will have been properly explained until we have understood why they are necessary for the animals' activity. In proposing this interpretation, however, I am (very tentatively) putting words into Lennox' mouth; it is a pity that he does not pursue the issue explicitly himself.

Lennox now asks readers to suppose that the ingredients of Aristotle's zoological investigation are indeed so integrated as to form a 'distinct scientific domain', and moves to his next question: how are we to conceive the relation in which it stands to other enquiries into nature? This introduces the longest and most fascinating section of his paper [59-65], based on clues provided by a second group of texts, 'those in which an investigation of animals is explicitly discussed, whether on its own or in comparison with other investigations' [60]. He focuses initially on passages from Meteorology 1.1 [339a59] and from De part.an. 1.1 and 1.4 [639a12-15, 644b16-20]. The first of these looks ahead to studies of animals and plants for which, Aristotle tentatively proposes, the work of the Meteorology may have prepared us: 'For having given an account of these things, we may perhaps have reached the goal we set before ourselves at the outset'. The second asserts that the purpose of De part.an. is to set certain

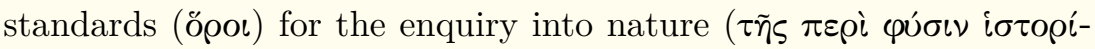
$\alpha \varsigma)$, 'such that by referring to them one can appraise the manner of its proofs'. The key point in the third is that Aristotle now claims

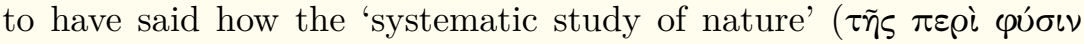

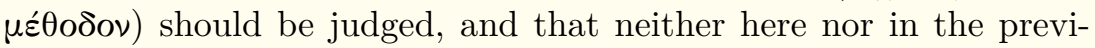
ous passage does he limit the scope of his assertion to the study of animals.

Concretely, it is clear that Aristotle's focus is entirely on animals; but it is the investigation of nature for which he claims to be providing standards of judgement. [61]

How, then, could Aristotle justify his apparent thesis that it is the study of this special class of natural beings, those that are alive, which can set standards for the study of nature as a whole? Lennox 
proposes [62] that his viewpoint is similar to one memorably enunciated by G. G. Simpson, in a passage which struck me very forcefully when I first read it some 40 years ago.

I suggest that both the characterization of science as a whole and the unification of the various sciences can most meaningfully be sought ... not through principles that apply to all phenomena but through phenomena to which all principles apply. ...I have, I believe, sufficiently indicated what those latter phenomena are: they are the phenomena of life. Biology, then, is the science that stands at the center of all science. [Simpson 1964, 107]

As applied to Aristotle, the point is that the study of living things must depend both on the methodological 'standards' or principles that apply to the study of nature in general and all other domains within it, and on principles peculiar to itself. This is true of no other field of enquiry. Hence, 'only a fully articulated zoological method will provide us with a complete set of standards for natural science' [62]. This, as it seems to me, is a very appealing interpretation of the Aristotelian evidence; and at the same time, as Simpson believed, a worthwhile (though no doubt highly debatable) challenge to modern scientific orthodoxies.

In the remainder of this part of the paper [63-65], Lennox considers the relations between Aristotle's zoological studies, his work in the Meteorology, and his investigations in the De anima and the Parva naturalia. I shall not examine the details of his discussion, which revolves mainly around passages from On Length and Shortness of Life [467b5-9], from De sensu [436a1-4], ${ }^{10}$ from Meteor. [389b23-8], and from De part. an. [390b15-22], in addition to some on which he has already drawn. Summarily, his conclusion is that

Aristotle sees the study of animals as both continuous with certain other natural investigations and yet distinct in subject matter, methods and principles.

The Meteorology provides information about 'elemental compounds and their emergent dispositions and interactions' which is essential

10 This passage, as Lennox notes, seems to pose 'insuperable problems' for the view he proposes; but he resolves them persuasively [63-64]. 
to the zoological works; but since it says nothing about these compounds' roles in living things or the functions or purposes of the animal parts formed from them, it is a 'prolegomenon' to the study of animals rather than a part of it. As to the De anima and its sequel, the Parva naturalia, which examine the nature and activities of the soul as such and the activities of the complex entity we might call 'ensouled body',

Parva Naturalia is characterized both as dependent upon De Anima and, at least in part, a sort of capstone of the investigation of animals. [65]

This last statement seems distressingly vague, and the details of Lennox' discussion do little to dispel the obscurity; he returns briefly to the issue at the end of his paper.

The penultimate section of the paper [66-68] considers a question suggested by the relation between the Meteorology and the studies of animals. The former is not included among the latter, but it provides resources on which the latter draw. How, then, are we to understand 'this sharing of resources across disciplinary boundaries'? Lennox addresses the problem on the basis of three texts which refer to a relation between two other 'distinct but related disciplines', natural philosophy and medicine [De sensu 436a18-436b2; De part. an. $653 \mathrm{a} 1-3,8-10 ;$ De respiratione 480b22-31]. The general upshot of these passages is that it is the role of a natural philosopher to investigate, theoretically, the principles of disease and to provide the science of medicine with the results of this enquiry. It is important to notice that this task is not hived off to a putative discipline of 'theoretical medicine' [66]. It is an intrinsic part of the business of natural philosophy, which will

study not only the causes of the proper functioning of the human organs, but also the causes of their malfunctioning or premature decay, and in general the causes of disease. These causes will be referred to and cited in medicine, but establishing these causes as the causes of disease is the task of the medically oriented physikos. [67]

These observations return us to the topic of Hankinson's paper, since Lennox suggests that the relation identified here between natural philosophy and medicine is much like the one posited in the 
Posterior Analytics between geometry and optics or between arithmetic and harmonics. 'The physician studies the fact, the physikos supplies the reason why' $[67-68] .{ }^{11}$ Thus, there are connections as well as differences ${ }^{12}$ between Aristotle's thoughts on the life-sciences and on the mathematical sciences to which the Posterior Analytics refers; but the conclusion Lennox draws about the relation between Hist. an. and the other zoological enquiries is different and perhaps more interesting. As he noted earlier, Hist. an. provides facts which 'causal investigations' such as De part. an. use and explain, and this makes the relation between them look identical with that between medicine and natural philosophy. But here the situation has changed. Hist. an., like the other zoological works, is concerned specifically with animals; the genos with which each is concerned is the same, and Aristotle makes no suggestion that two distinct sciences are involved here, one of which supplies first principles for the other. No borrowings from different domains are involved. Hence, there is a strong sense in which, by the criteria of the Posterior Analytics, the investigations undertaken in Hist. an., De part.an., and De gen.an. all belong to the same science [68]. But does the same hold of the De anima and its sequel, the Parva naturalia? Lennox leaves this question hanging, noting only that at least one part of their enquiry is clearly outside the scope of natural science.

The next two papers, by Philip van der Eijk and by Geoffrey Lloyd, take medicine as their principal subject. Van der Eijk's essay, 'Between the Hippocratics and the Alexandrians: Medicine, Philosophy and Science in the Fourth Century BCE' [72-109], ${ }^{13}$ focuses on a phase of Greek medicine to which scholars have typically paid less attention than to the Hippocratics and the Alexandrians; neither the relevant philosophical texts nor the fragmentary works of the strictly medical writers of this period have been well served. ${ }^{14}$ On pages 73-78 he lists 35 known authors (and one compilation, the

11 Lennox does not return to the relation between the Meteorology and the zoological works which prompted this part of his paper; but fairly clearly he would construe it in the same way.

12 One of the most important differences is indicated in the concluding part of the paper [69].

13 He includes a seven-page bibliography.

14 Van der Eijk mentions various honorable exceptions to this scholarly neglect [72-73nn1-3]. 
Problemata attributed to Aristotle) and the titles of a large number of their works; and the list, as he says, is not exhaustive. Clearly there is no shortage of material to be studied, even if much of these authors' work survives only in fragments or indirect allusions, or is completely lost.

An important point that emerges from this survey is that the interests of 'philosophers' and 'medical' writers overlap to a considerable, but also a variable extent. Van der Eijk issues a warning that the similarities and differences between them 'have to be identified and assessed from one individual case to another', and that it is inadequate and sometimes misleading to distinguish them under such general headings as 'practical vs. theoretical', 'clinical vs. scientific', and so forth [78]. He notes also that neither 'philosophy' nor 'medicine' unambiguously identifies any one definable project, and that ancient authors themselves not only quite often treated certain 'philosophers' as authorities on medicine, but were also well aware that the contours assigned to this discipline were changeable and continually disputed [79-80].

After these introductory remarks, the first topic considered is the treatment of medicine and the life-sciences in the fourth-century Academy and Lyceum [80-83] — or so the title of this section promises, though van der Eijk's comments on Plato are restricted to a reference to recent work by Vegetti [1995] and Lloyd [2003, 142-175], and Plato's successors in the Academy are not mentioned at all. Nor does he discuss the writings of Peripatetics other than Aristotle himself. His central theme, in fact, is the extent, diversity, and importance of Aristotle's own work in the field of medicine and on matters closely related to it. It made or inspired major empirical discoveries; it created a theoretical framework for the study of the workings, failings, and reactions of the human body; it made valuable contributions to the methodology of medical investigation and to the repertoire of concepts used to systematize and communicate medical knowledge; and it laid the foundations for an understanding of the discipline's historical development.

Van der Eijk offers several considerations which might help to explain how it came to do all this. First, Aristotle's familiarity with earlier medical thought led him to acknowledge the extent to which doctors had contributed (and were still contributing) to the study of 
nature, and to comment frequently on their ideas. Then, there is the intimate connection, touched on in Lennox' paper, which Aristotle himself recognizes between medicine and natural science. Thirdly, van der Eijk contends, we should take seriously the fact that later writers credit Aristotle with several specifically medical works and a number of medical doctrines, arguing that there is no better reason to reject their authenticity than

a tacit distinction between 'philosophy' and 'science' and the assumption that these writings were too 'specialized' and 'unphilosophical' for the mind of Aristotle.

After all, as he points out, there is plenty of 'specialized' or 'technical' matter in Aristotle's surviving treatises [82-83]. The section ends with a catalogue of the major benefits that would be gained if scholars studying later phases of medical history were to give full weight to the impact made on it by Aristotelian thought; conversely, a wellgrounded understanding of Aristotle's medical work would help us to appreciate the ways in which later developments in medicine affected the interpretation of his writings in general, both inside and outside the Aristotelian tradition. All this is admirable, and points forward to research which, he tells us, is ongoing but still in its early stages. I can only add that it will not be complete until it also takes fully into account the work done in the Academy throughout the same periods of history.

In the remainder of his paper, van der Eijk brings into the center of the picture the people normally classified as fourth century 'medical writers' rather than 'philosophers'. After a general survey of relevant features of their work, he devotes separate sections to each of three individuals, Diocles, Praxagoras, and Mnesitheus, followed by more detailed discussions of their most significant contributions (and those of some others) to debates outside the strictly medical sphere. These include refinements of the procedures of classification and division; the development of a classificatory terminology; analyses of the distinctions, in pathology, between signs, symptoms, and causes; advances in empirical research; and negotiations between the claims of reason and experience as sources of knowledge. His comments on all these matters are solidly grounded in the surviving texts, several of which - including some of the most intriguing - will probably be unfamiliar to non-specialist readers. 
I shall not go into the details. It is enough to say that van der Eijk makes a very compelling case for the thesis that a substantial amount of these doctors' work was devoted to issues well entrenched in the philosophers' agenda, particularly in epistemology. Whether they contributed original and worthwhile insights of their own in these areas is another question; the evidence presented here is not enough to underwrite a confident affirmative answer (except, perhaps, in so far as Diocles' delicate balancing-act between theoretical and empirical criteria of judgement can be viewed in that light); but it is certainly enough to encourage further research into the matter. Van der Eijk's paper as a whole, in fact, challenges students of ancient philosophy to push their investigations out into this underdeveloped territory. In doing so, I suggest, they should take proper account of a point that he makes [86] which may seem tangential, that these writers were in the business of expanding their field of operation not only into philosophy but into many other, less intellectually high-profile areas too, writing on topics as diverse as child-rearing, cookery, etiquette, flower-wreathing, and seafaring. Though their interest in philosophy no doubt had deeper roots, it is worth considering the extent to which their pronouncements upon it, like these apparently more trivial exercises, were motivated by their wish 'to have a finger in a large number of pies and to address a wider clientele', so 'disseminating their ideas more widely and having greater influence on society'.

G. E. R. Lloyd's paper [110-130] is entitled 'Mathematics as a Model of Method in Galen'. The problem that it addresses can best be brought out in his own words:

On the one hand he [Galen] often expresses his admiration for the mathematicians' methods. They provide his star examples of the highest type of demonstration, 'epistemonic apodeixis', securing certainty. On the other hand to illustrate those methods Galen gives a bewildering array of examples that do not all by any means conform to the patterns set by Euclid in the Elements... The issue I wish to explore here is how clear a grasp of mathematical method does Galen have? Or rather, since we should look at the problem from his point of view, what counts as 'mathematical method' in Galen's eyes? The question derives its importance from the frequency with which mathematics is held up as an ideal: but 
quite what that ideal comprises is more difficult to pin down than is generally recognized. [100]

Lloyd begins [111-117] by examining passages in which Galen professes his allegiance to mathematical methods of proof,,$^{15}$ sometimes explaining also why, in certain cases, he has not exploited them. One reason why he does not always provide such proofs, as he says in various passages of On the Usefulness of Parts, is that many of his potential readers cannot abide such things: he is inclined to avoid loading his writings with 'demonstrations requiring astronomy, geometry, music, or any other logical discipline, lest my books should be held in utter detestation by physicians' [De usu part.10.14 in Helmreich 1907-1909, 3.837.9-12]. In other cases he admits his inability to find such a proof, either by questioning other philosophers or through his own efforts. ${ }^{16}$ In all the relevant passages, however, Galen treats mathematical proof as the ideal to which scientists should aspire, repeatedly assigning this status, specifically, to proofs in geometry, and distinguishing such demonstrations sharply from arguments of a dialectical, rhetorical, or sophistic sort. The central points that Lloyd derives from these texts are that not all the arguments to which Galen approvingly refers are strictly geometrical, and - more importantly - that although those of Galen's own arguments to which he assigns the status of 'epistemonic apodeixeis' may be logically sound, there is nothing specifically mathematical about them.

Lloyd now looks more closely at details of Galen's comments on mathematical arguments, and of the specimens that he chooses to exemplify them, paying particular attention to the status of their premises. The texts which he cites first show clearly that Galen understood the requirement that scientific demonstrations, in medicine as elsewhere, must be based on premises that are indemonstrable, 'evident', and self-justifying, and more generally that he seems to have had 'an impressive grasp of axiomatic-deductive reasoning, proceeding from indemonstrable primary premises, via valid arguments, to

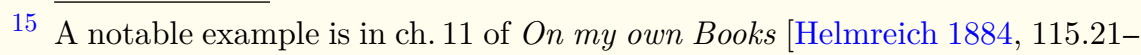
117.20], in which he recalls how his grasp on mathematics rescued him from the perils of scepticism.

16 See ch. 6 of On the Construction of the Fetus [Kühn 1821-1823, 4.695.1696.3]. 
incontrovertible conclusions' [117-118]. But there are troublesome complications. Sometimes, it turns out, Galen is prepared to attempt proofs of propositions that he has claimed as primary and evident, thus falling foul of Aristotle's carefully argued contention that the primary premises of a demonstration must be incapable of proof [Post. an. 72b5ff.]. Elsewhere, his illustrations of mathematical method frequently involve observational premises, which of course cannot be evident and self-justifying in the same way as mathematical axioms, and in some cases are not even evident 'in the way that Galen claims that what is actually hot is evident to the sense of touch' [121]. ${ }^{17}$ Various other peculiarities arise too, mainly from the mixture of mathematical and empirically based propositions in the supposedly exemplary demonstrations. As Lloyd points out,

the recurrent problem... is that once axiomatic deductive demonstrations are attempted in such fields as physics, cosmology, or medicine, finding good-looking principles that can be claimed as self-evident is extremely difficult;

the medical 'principle' he mentions here, for example, will turn out, on different interpretations, to be 'either controversial or vacuous' [120]. An especially striking oddity in Galen's approach appears in passages where he calls on observation to confirm results predicted by mathematical reasoning [123-124]. One might wonder why such reasoning should stand in need of empirical confirmation, and in what sense the whole of the resulting demonstration, including the confirming observation, could be considered 'mathematical'. But it is worth noting (though Lloyd does not mention the point) that Galen's strategy here has affinities with the procedure adopted by Ptolemy in his Harmonics, and might perhaps be understood in a similar way. ${ }^{18} \mathrm{Cal}-$ culations based on mathematical principles will generate indisputable results; but it is only if these results tally with our observations of

17 The passage cited here (from On the Opinions of Hippocrates and Plato 8.1) involves astronomical observations made with the help of a dioptra.

18 Likewise, one might also recall the Stoic concern with the use of logic and mathematics in addressing the problem of getting knowledge of objects that are not immediately evident, a use expounded in part by Cleomedes in his Caelestia, for example. 
the phenomena that we can be sure that they were the right principles to apply in this particular case. ${ }^{19}$ In Harm. 3.3 [Düring 1930, 91.22-94.20], Ptolemy represents the study of harmonics, conducted in the manner which his treatise commends and exemplifies, as an intrinsic part of mathematics, and reflects on the relations between reason and the senses of sight and hearing in such enquiries; and it would be interesting to compare the conception of the mathematical disciplines outlined in this passage with the one implicit in Galen's usage.

Lloyd considers, finally, 'the most sustained stretch of applied geometry in the Galenic Corpus' [124-127], the discussion of optical problems at the end of De usu part.11. He notes the impeccable credentials of the geometry itself; but here again the passage runs into difficulties in its application of the theorems to the cases in hand. Most problematically, the forms and arrangements of the eye's parts and the course of the optic nerves which are implied by application of the geometry to them are not always consistent with one another; and on several occasions - and in several respects - the geometry fails to correspond to physical facts of which Galen was fully aware. In these cases, it is hardly possible to treat the geometrical models even as idealizations of the empirical facts, as may sometimes be appropriate elsewhere.

As we have come to expect, Lloyd guides his readers confidently through the tangled forests of the texts he discusses, pointing out and identifying the specimens of unusual fauna and flora encountered along the way and lucidly explaining their peculiarities. This marriage of medicine and mathematics has evidently produced some strange hybrids. Readers may reasonably wonder whether similar monsters emerge also from other scientific projects of the period, and if so, just how similar they are. Perhaps, as my allusion to Ptolemy

19 Thus, Ptolemy finds no fault in the mathematical reasoning of the harmonic theorists whom he calls 'Pythagoreans'; but the fact that their conclusions do not correspond to the observed phenomena shows that the principles from which their reasoning flowed were inappropriate to the subject matter in question [see, e.g., Düring 1930, 6.1-5, 13.1-25]. Cf. Barker 2000, 26-29. 
may have suggested, Galen's apparently cavalier treatment of mathematics reflects a general conception of the discipline that might have seemed less odd to his contemporaries than it does to us. ${ }^{20}$

The last two papers in the collection examine relations between musical science (primarily harmonics) and philosophy in the work of the Neoplatonists. In the first few pages of his erudite essay, 'The Music of Philosophy in Late Antiquity' [131-47], Dominic O'Meara emphasizes the influence of 'Pythagorean' and, hence, mathematical thought on late forms of Platonism, noting the pivotal role played by Nicomachus in setting its musical and mathematical agenda and putting in place the distinction between the 'empirical' harmonics of Aristoxenus and the 'rational' mathematical harmonics of the Pythagoreans [131-133]. He sketches Boethius' (and probably therefore Nicomachus') distinction between cosmic, human, and 'instrumental' music - where 'human' music concerns the structures of soul and body and the relation between them, and 'instrumental' music is music in our normal sense of the term - and he explains why it is the third of these that is the main subject of Pythagorean analysis. ${ }^{21}$ He then explores the Nicomachean and Neoplatonist account of the place of harmonics among the mathematical sciences [133-135], from which it emerges inter alia that it is subordinate to arithmetic, and that whereas arithmetic is concerned with number or plurality in itself, 'Pythagorean music deals ... with relations between numbers or finite pluralities' [135].

This leads to an important question: 'Pluralities of what?' Despite the fact that Iamblichus speaks of music as articulating relations between sounds, O'Meara denies that he means that sounds are the object of this science's studies, relating it instead, in a fascinating passage [135-136], to Iamblichus' discussion of the objects of the mathematical sciences in general [De comm. math. 10], with the help of explanations offered later by Syrianus and Proclus. Mathematical objects are concepts articulated through arithmetic and geometry.

20 One might also usefully recall Aristotle's example of an application of geometry to medicine, and Hankinson's discussion of it at the end of his paper.

21 I am unconvinced, however, by his use of Porphyry [Düring 1932, 5.21-27] in the course of his explanation. There is no reason to assume, as he does, that the ideas reflected there are Pythagorean; the relevant part of the passage is in fact a close paraphrase of Aristoxenus [see Da Rios, 1.5-8]. 
They are 'discursive conceptual projections of higher truths, present to the soul as above discursive reason and as innate in the nature of soul'. They 'exist in soul, but are not identical with soul: they are the way soul elaborates a discursive scientific knowledge of its own constitution'. This can be understood fairly straightforwardly so far as the objects of musical science are concerned, on the basis of material in the Timaeus where it is clear that in exploring musical relations the soul is developing discursive knowledge of its own structure. Thus, although the same relations may be expressed in audible sounds, they are not what 'Pythagorean music', as O'Meara calls it, is really about.

This part of the paper concludes [137-139] by explaining the mathematical procedures involved in this science, and discussing some of their key concepts and their sources (not always their earliest sources, but those that formed the immediate background to the Neoplatonists' work). The remainder [139-146] considers questions about the ways in which music, so conceived, was used in Neoplatonist philosophy. One is in philosophical education, on which O'Meara [139] quotes Calcidius: 'Music orders the soul rationally, calling her back to her former nature and making her at last into what she was when god at first made her' [Waszink 1975, 273.2-3]. In Neoplatonist thought, this 'assimilation of the soul to divine life' is the goal of philosophy, and the various disciplines in their philosophical curriculum are 'stages in a progressive scale aimed at the transformation and divinization of the soul', starting from education in the commonplace forms of moral virtue and proceeding upwards to the purificatory and intellectual virtues. Music contributes at two levels, both in the initial stages of ethical training and as one of the higher, theoretical sciences $[140] .{ }^{22}$

Since the lower educational level is the subject of Anne Sheppard's paper in this volume, O'Meara restricts his comments on it to identifying its role in Neoplatonist thought as a preparatory sort of

22 O'Meara notes that these contributions correspond roughly to those identified by Plato: (i) to the role of music in Republic 2-3 and (ii) 'to the role assigned to mathematical science in the image of the line at the end of book VI'. It strikes me as odd that he does not mention the more detailed and extremely relevant discussion of the mathematical sciences, including harmonics, in book 7 . 
'moral edification', and citing two familiar stories (about the use of music by Pythagoras and by Hypatia of Alexandria to cure people of erotic passion) to illustrate the way in which it supposedly worked [140-141]. As to the higher level, the role of music, like the other mathematical sciences, is to help us to bridge the gap between knowledge of the physical world and the knowledge of immaterial being to which philosophy aspires. Iamblichus and Proclus develop the idea that

mathematics anticipates, foreshadows, the science above it, metaphysics, as if an image of it, just as mathematics represents itself as a kind of paradigm of the sciences below it.

Here the Neoplatonists are very clearly building on the picture sketched in Plato's image of the line. O'Meara finds indications in these philosophers' writings of the significance of musical science for two of the strictly philosophical disciplines, theoretical ethics and physics [142].

Central concepts in Iamblichus' account of ethics are those of measure, completeness, unity, proportionality, and harmony, all of which can be related to musical thought, and in particular to 'the Pythagorean concept of concord' (though one might add that many of the relevant facets of this conception are by no means restricted to the Pythagorean tradition). In elaborating this point through the examination of passages in Proclus and Damascius [143-145], O'Meara shows how Neoplatonist writers sometimes attempted to establish close correlations between particular virtues (specifically, those discussed by Plato in Republic 4) and particular musical concords, inspired in part by Plato's own words in Rep.430e and 431e, while drawing also on the Pythagorean representations of these concords as ratios of numbers. It also emerges very clearly that Proclus' and Damascius' views on the matter are irreconcilably different; and the issue between them seems undecidable. For O'Meara, however,

the important point ... is that in approaching ethical concepts, the late Neoplatonists could find in music a theory of relations, of structure and in particular of unification, which influenced the way in which they saw the moral life, a life whose paradigms, they believed, were to be found in a higher theoretical science, in music. [145] 
His closing comments on the relation between music and physics [145-146] are brief but important. The central point is that the main task for which Pythagorean musical theory is used in this context, notably by Proclus, is in the service of attempts to understand 'the extraordinary richness of Plato's harmonical accounts of the constitution of the soul and of the world' in the Timaeus: witness the fact that Proclus' vast commentary on the dialogue 'is to a considerable extent devoted to presenting Pythagorean music in connection with explaining the production of soul and of the world' [145]. A full reconstruction of the Neoplatonist understanding of musical theory and its integration with their accounts of these matters is yet to be attempted.

Greek harmonics, and late Platonist treatments of it in particular, are unfamiliar ground to many students of ancient philosophy and science, and I sympathize with the need O'Meara has evidently felt to devote much of his paper to basic essentials of a sort that can be dispensed with in studies of better-known areas of Greek thought. This has inevitably squeezed out many details which might fruitfully be examined. ${ }^{23}$ But anyone embarking on a fuller exploration of this relatively uncharted territory will find the paper a valuable point of departure.

Anne Sheppard's paper, 'Music Therapy in Neoplatonism' [148155], originated as a response to O'Meara's. Its scope is a good deal wider than its title suggests, since she considers an extensive range of ways in which Neoplatonists supposed that music can affect our emotions and dispositions; and she treats its educational uses as the central case. ${ }^{24}$ At least some Greek theorists drew distinctions, as we might ourselves, between strictly therapeutic procedures and others. Thus, Aristides Quintilianus in his De musica (whose second

23 Apart from closer study of the issues that he mentions, I miss in particular any reference to the epistemological and logical problems arising in connection with harmonic science, which interest Porphyry so deeply in his commentary on Ptolemy's Harmonics. Whether these interests are reflected in similar contexts in the writings of later Neoplatonists I do not know; it is another question that invites further research.

${ }^{24}$ She even includes uses of music which we might describe as only circumstantially beneficial, as when Synesius is said to have routed an army of barbarians by musical means when they were attacking Cyrene [153]. There is evidently nothing 'therapeutic' about this. 
and third books place him at least in the penumbra of Neoplatonism) divides ethical education $\pi \alpha i \delta \varepsilon v \sigma \iota \varsigma$ into two types, therapy ( $\tau$ ò

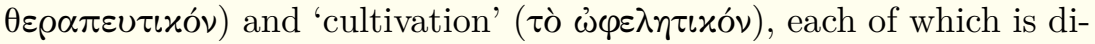
vided in two again. The objective of therapy is to cure actual evils in the soul (in either of two ways); that of cultivation is to instill in young people virtues that they have not yet developed, or, in its second guise, to strengthen and preserve good dispositions that are already in place [Winnington-Ingram 1963, 68.22-69.1]. Education, as conceived in Republic 3, clearly falls under the latter heading; Plato says nothing there about eradicating vices already present in the soul. One might argue, of course, that for a Neoplatonist ethical education is indeed a kind of therapy, helping to release the soul from the afflictions brought upon it by its embodiment. But it would be perverse, in any case, to complain about the paper's extensive scope.

Sheppard begins [148-149] from a passage of Proclus' commentary on the Republic [Kroll 1899-1901, 1.56.20-60.13: esp. 1.58.27-

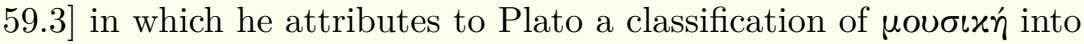
four types. The first two are philosophy and inspired poetry; Sheppard [148-149] identifies the third with the 'Pythagorean music' discussed by O'Meara, and the fourth as music of the lower kind to which he briefly refers [140-141], whose role is the education of the emotions. This is clearly right; Proclus, as she says, relates the fourth kind of music explicitly to Plato's discussion in Rep. 3 .

Before any further consideration of Neoplatonist texts, Sheppard surveys ideas current in the fifth and fourth centuries BC about the uses to which music's emotional power can be put (mentioning Damon, Aristophanes, Plato, Aristotle, and Theophrastus in particular). 'Somewhere in the period between Theophrastus and the Neoplatonists', she goes on, 'the idea that music can be used for the therapy of the passions became associated with Pythagoreanism' [150]. It is just possible, I suggest, that the association originated with Plato's immediate successors in the Academy; but her comment is a salutary reminder of the unreliability of our evidence for such an idea in the early Pythagorean tradition. She then offers arguments, based on a hypothesis of Thomas Mathiesen [1983] about Aristides Quintilianus and on her reading of a passage in Iamblichus De mysteriis, for the view that the conception of two kinds of music, Proclus' third and fourth, was introduced into Neoplatonism by Porphyry; and while the case is not proven, I find her reasoning persuasive. 
Her brief discussion of another passage of Proclus [Kroll 18991901, 1.60.14-63.15] deserves a special mention [152]. Proclus is considering the harmoniai and rhythms which Plato thought useful in education, and trying to answer Aristotle's criticism of Plato on the topic of the Phrygian harmonia [Pol.1342a-b]. She notes that it amounts to 'a typical piece of late Neoplatonist exegesis, assuming unity in Plato's thought and seeking to reconcile Plato and Aristotle'. Quite so. But her more intriguing and very well taken point is that Proclus' argument turns in part on ideas about religious ritual and divine possession, which are prominent in Iamblichus, as she has already said [151], and indeed pervasive in Neoplatonism, but of course make no appearance in Plato's discussion at this point in the Republic. It is a fascinating example of the ways in which Neoplatonists wove together threads drawn from a very wide range of original contextsboth within the writings of the philosopher they were studying and outside them - to create their extraordinary philosophical synthesis.

Sheppard's closing remarks [154] are worth quoting.

A full account of Neoplatonic views of music would need to cover both the scientific and the therapeutic kind. Music is, after all, a complex phenomenon: regarded nowadays as one of the arts, it is nevertheless susceptible both to scientific analysis and to philosophical study. It should come as no surprise that the Neoplatonic view of music reflects that complexity.

To echo the final words of Lennox' paper [70], 'Amen to that'.

This has been a long review of a short book. As I said at the start, no compendious conclusions emerge from it. Its signal virtue is that each of its contributors has outlined, in more or less detail, a set of problems concerned with the relations between the sciences and between them and philosophy; and both the overall issues and the problems which they identify are of genuine importance. None of them, I think, would claim to have definitively solved them; what they do is to set a massive agenda for further and urgently needed research. The book will be of great value to anyone who tries to undertake any part of it. 
BIBLIOGRAPHY

Barker, A. 2000. Scientific Method in Ptolemy's Harmonics. Cambridge. bridge

2007. The Science of Harmonics in Classical Greece. Cam-

Barnes, J. 1994. Aristotle: Posterior Analytics. 2nd edn. Oxford.

Da Rios, R. 1954. Aristoxeni elementa harmonica. Rome.

Düring, I. 1930. Die Harmonielehre des Klaudios Ptolemaios. Göteborg.

1932. Porphyrios Kommentar zur Harmonielehre des Ptolemaios. Göteborg.

Gotthelf, A. 1988. 'Historiae I: Animalium et Plantarum'. Pp. 100135 in W. W. Fortenbaugh and R. W. Sharples edd. Theophrastean Studies. New Brunswick.

Helmreich, G. 1884. Claudii Galeni scripta minora. vol. 2. Leipzig. 1907-1909. Galeni de usu partium. 2 vols. Leipzig.

Kroll, W. 1899-1901. In Platonis rempublicam commentarii. 2 vols. Leipzig.

Kühn, K. G. 1821-1823. Claudii Galeni opera omnia. 22 vols. Leipzig.

Lennox, J. G. 1986. 'Aristotle, Galileo and the "Mixed Sciences"'. Pp. 29-51 in W. A. Wallace ed. Reinterpreting Galileo. Washington, DC. 2001. Aristotle's Philosophy of Biology. Cambridge.

Lloyd, G. E. R. 2002. 'Le pluralisme de la vie intellectuelle avant Plato'. Pp. 39-54 in A. Laks and C. Louguet edd. Qu' est-ce que la philosophie présocratique / What is Presocratic Philosophy? Lille.

2003. In the Grip of Disease. Oxford.

Mathiesen, T. J. 1983. Aristides Quintilianus: On Music, in Three Books. New Haven.

McKirahan, R. 1992. Principles and Proofs. Princeton.

Ross, W. D. 1949. Aristotle's Prior and Posterior Analytics. Oxford. 
Sharples, R. W. 2005. ed. Philosophy and the Sciences in Antiquity. Burlington, VT/Aldershot, UK.

Simpson, G. G. 1964. This View of Life: The World of an Evolutionist. New York.

Vegetti, M. 1995. La medecina in Platone. Venice.

Waszink, J. H. 1975. Calcidius. Commentarium in Timaeum. London/Leiden.

Winnington-Ingram, R. R. 1963. Aristides Quintilianus. De musica. Leipzig.

Zhmud, L. 1994. 'Die Beziehungen zwischen Philosophie und Wissenschaft in der Antike'. Sudhoffs Archiv 78:1-13. 